\title{
Pelatihan Microsoft Excel Tingkat Menengah Untuk Guru-guru SD Taruna Bakti Bandung
}

\author{
Henri Septanto1), Paramaresthi Windriyani ${ }^{2)}$, Tedi Lesmana Marselino ${ }^{3)}$ \\ Informatika, Institut Teknologi dan Bisnis Kalbis \\ Jl. Pulomas Selatan Kav.22, Jakarta Timur 13210 \\ ${ }^{1)}$ Email: henri.septanto@kalbis.ac.id \\ 2)Email: paramaresthi.windriyani@kalbis.ac.id \\ 3)Email: tedi.lesmanai@kalbis.ac.id
}

\begin{abstract}
Teachers in their daily work besides being involved in teaching and learning activities must also process the value data as a form of report on the results of the teaching and learning process they have done. Training in using Microsoft Excel Application Software for Data Processing is the right choice because the application software has been very popular, almost all computer users use the application software for data processing, ranging from simple data processing to complex and complex data processing. The purpose of the Microsoft Excel Intermediate Level Training in PKM activities is to improve the competence of the Taruna Bakti Elementary School Teachers in the field of data processing. Teacher competency improvement in the field of data processing will be very useful in supporting their performance because with competence in the field of data processing their work will be more efficient and effective. Based on this, teacher competence in the field of data processing is very necessary, because these competencies can support the performance of teachers in their daily work.
\end{abstract}

Keywords: competence, data processing, microsoft excel, teacher, training

Abstrak: Para Guru dalam pekerjaan sehari-harinya selain terlibat dalam kegiatan belajar mengajar juga harus mengolah data nilai sebagai bentuk laporan hasil dari proses kegiatan belajar mengajar yang telah mereka lakukan. Pelatihan penggunaan Software Aplikasi Microsoft Excel untuk Pengolahan Data adalah pilihan tepat karena software aplikasi tersebut sudah sangat populer, hampir semua pengguna komputer menggunakan software aplikasi tersebut untuk pengolahan data, mulai dari pengolahan data sederhana sampai dengan pengolahan data yang rumit dan kompleks. Tujuan dari Pelatihan Microsoft Excel Tingkat Menengah dalam kegiatan PKM ini adalah untuk meningkatkan kompetensi para Guru SD Taruna Bakti dalam bidang pengolahan data. Peningkatan kompetensi Guru dalam bidang pengolahan data akan sangat bermanfaat dalam menunjang kinerja mereka karena dengan kompetensi dalam bidang pengolahan data pekerjaan mereka akan lebih efisien dan efektif. Berdasarkan hal tersebut maka kompetensi guru dalam bidang pengolahan data sangat diperlukan, karena kompetensi tersebut dapat menunjang kinerja guru dalam pekerjaannya sehari-hari.

Kata kunci: guru, kompetensi, pelatihan, pengolahan data, microsoft excel

\section{PENDAHULUAN}

Teknologi Informasi dan Komunikasi berkembang dengan sangat pesat, ditambah dengan masuknya era Revolusi Industri 4.0 menekankan pada ekonomi digital, artificial intelligent dan robotic secara tidak langsung menuntut dunia pendidikan untuk mengonstruksikan kreativitas, pemikiran kritis, penguasaan teknologi dan literasi digital [1].

Era Revolusi Industri 4.0 ini juga menuntut dunia pendidikan untuk dapat beradaptasi, guru sebagai garda terdepan harus mampu meningkatkan kompetensinya baik dalam hal kemampuan metodologi pengajarannya mau kemampuan teknis yang berhubungan dengan penggunaan aplikasi sebagai penunjang proses pembelajaran.

SD Taruna Bakti berdiri sejak tahun 1956, hingga saat ini masih konsisten dalam membentuk peserta didik menjadi pribadi yang berprestasi, cerdas, terampil, sopan, santun, jujur dan ramah. Kurikulum yang memotivasi peserta didik untuk aktif dan berprestasi digunakan SD Taruna Bakti, serta kegiatan belajar mengajar dilakukan secara optimal. Selain itu sekolah memfasilitasi kebutuhan 
pengembangan diri pesera didik melalui kegiatan ekstrakurikuler yang beragam dan ditunjang dengan sarana belajar yang memadai. [2]

SD Taruna Bakti yang merupakan salah satu lembaga pendidikan tingkat dasar di Bandung melihat betapa pentingnya meningkatkan kompetensi guru-gurunya dalam bidang penggunaan aplikasi yang menunjang pekerjaan guru. Untuk itu pihak SD Taruna Bakti mengadakan kerjasama dengan Tim Dosen Program Studi Informatika, Fakultas Industri Kreatif, Institut Teknologi dan Bisnis Kalbis untuk mengadakan Pelatihan Microsoft Excel Tingkat Menengah Untuk Guru-guru SD Taruna Bakti, Bandung, Jawa Barat, dapat dilihat pada Gambar 1.

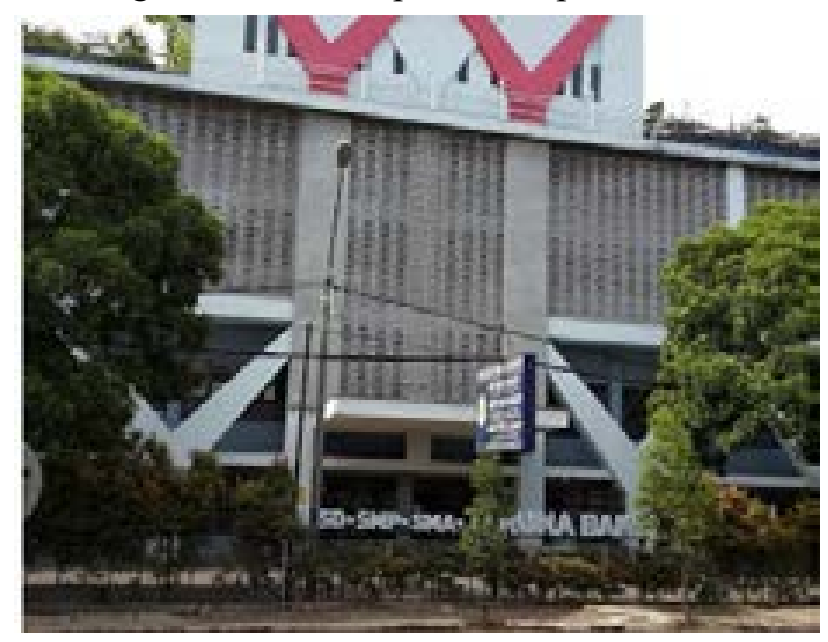

Gambar 1 SD Taruna Bakti

Persoalan yang dihadapi oleh para guru SD Taruna Bakti adalah dalam hal pengolahan data, khususnya dalam hal pengolahan nilai. Buku-buku tentang tutorial penggunaan Software Aplikasi untuk pengolahan data memang banyak dijual, namun memang harus diakui bahwa tidak banyak orang yang mampu belajar secara otodidak, untuk itulah pelatihan penggunaan Microsoft Excel untuk keperluan pengolahan data sangat dibutuhkan oleh para guru SD Taruna Bakti.

Software Aplikasi Microsoft Excel dipilih sebagai materi pelatihan dengan pertimbangan bahwa Microsoft Excel adalah para guru SD Taruna Bakti sudah terbiasa menggunakan Microsoft Excel selain itu software aplikasi tersebut sudah tersedia pada komputer sekolah dan juga sudah terinstal pada laptop guru-guru tersebut.

Permintaan materi Pelatihan Microsoft Excel Tingkat Menengah ini dipilih oleh pihak SD Taruna Bakti karena dianggap akan menunjang pekerjaan para guru SD karena mereka membutuhkan kemampuan penggunaan aplikasi Microsoft Excel untuk keperluan pengolahan nilai dan berbagai keperluan lainnya yang berhubungan dengan tugasnya sebagai guru.

\section{METODE PELAKSANAAN}

Metode Pelaksanaan Kegiatan Pengabdian Masyarakat yang dilakukan berupa pemberian Workshop (Pelatihan) penggunaan Software Aplikasi Microsoft Excel. Kegiatan pelatihan ini bertujuan untuk meningkatkan kompetensi para guru SD dalam mengolah data, khususnya data-data yang berhubungan dengan pengolahan nilai murid-murid SD Taruna Bakti.

Materi Pelatihan yang diberikan adalah penggunaan Software Aplikasi Microsoft Excel Tingkat Menengah sesuai dengan permintaan dari pihak sekolah karena pada dasarnya para guru sudah memiliki pengetahuan dan kompetensi dasar dalam penggunaan software aplikasi Microsoft Excel, hanya saja kompetensi perlu ditingkatkan lebih spesifik lagi khususnya dalam bidang pengolahan data.

\section{A. Tahapan Pelaksanaan Kegiatan}

\section{Perencanaan Kegiatan PKM}

Perencanaan kegiatan PKM ini didiskusikan dalam rapat Tim Dosen Prodi Informatika beberapa bulan sebelum pelaksanaan PKM.

\section{Observasi Awal}

Observasi awal dilaksanakan setelah perencanaan kegiatan PKM. Tim Dosen Prodi melakukan observasi awal ke SD Taruna Bakti. Tujuan observasi awal ini adalah untuk mengetahui permasalahan dan kebutuhan para Guru SD Taruna Bakti terkait dengan materi pelatihan yang akan diberikan

\section{Penawaran Kerjasama}

Setelah observasi awal dilakukan maka Tim PKM menawarkan kerjasama untuk mengadakan "Pelatihan Microsoft Excel Tingkat Menengah untuk Guru-guru SD Taruna Bakti.

\section{Penerimaan Kerjasama}

Kepala SD Taruna Bakti selaku pimpinan menerima penawaran kerjasama PKM yang ditawarkan oleh tim PKM.

\section{Penyusunan Proposal dan Materi Pelatihan}

Berdasarkan observasi yang telah dilakukan maka Proposal dan Materi Pelatihan yang dihasilkan adalah Pelatihan Microsoft Excel Tingkat Menengah untuk para Guru SD Taruna Bakti.

\section{Penugasan PKM}

Penugasan PKM kepada Tim PKM dibuat dan ditandatangani oleh Kaprodi Informatika 


\section{Koordinasi PKM}

Koordinasi pelaksanaan PKM dilakukan antara Tim PKM dengan Mitra dilakukan melalui telepon dan email.

\section{Pelaksanaan Kegiatan PKM}

Pelaksanaan PKM dilakukan pada Rabu, 10 September 2019, jam 8.00 s.d 16.00 WIB di SD Taruna Bakti Bandung.

\section{Evaluasi dan Pembuatan Laporan Akhir}

Evaluasi dilakukan setelah pelaksanaan Kegiatan PKM dilakukan untuk membahas permasalahan serta kekurangan yang ada selama pelaksanaan PKM yang bermanfaat sebagai pembelajaran untuk pelaksanaan PKM berikutnya. Laporan akhir dibuat sebagai bentuk pertanggungjawaban terhadap pelaksanaan PKM yang telah dilakukan.

\section{B. Teknik Pengumpulan dan Analisa Data}

\section{Teknik Pengumpulan Data}

Data yang diperlukan terkait dengan pelatihan untuk para guru SD Taruna Bakti didapat melalui:

a. Dokumentasi

Dokumentasi didapat dari website Kemendikbud dan juga dokumen internal yang dimiliki oleh Mitra. b. Observasi

Observasi dilakukan dengan mengamati kegiatan yang dilakukan para guru, khususnya saat mereka menggunakan komputer untuk keperluan pengolahan data.

c. Wawancara

Wawancara dilakukan dengan melakukan tanya jawab kepada Kepala Sekolah, Wakil Kepala Sekolah dan beberapa guru di SD Taruna Bakti Bandung. Tujuan dari wawancara ini adalah agar diperoleh informasi yang detail tentang kebutuhan pelatihan yang akan dilakukan.

d.Survei

Survei dilakukan dengan memberikan daftar pertanyaan sebelum dan sesudah PKM dilakukan kepada para guru SD Taruna Bakti. Survei sebelum PKM dilakukan bertujuan untuk mengetahui pelatihan apa yang dibutuhkan oleh mitra PKM, sedangkan survei setelah PKM dilakukan untuk mendapatkan masukan dan informasi tentang kekurangan dan kelebihan PKM yang telah dilaksanakan dari para peserta pelatihan agar PKM yang akan datang dapat menjadi lebih baik lagi.

\section{Analisa Data}

Rincian data profile SD Taruna Bakti [3] a. Jumlah Murid, seperti pada Tabel 1.
Tabel 1 Jumlah Murid berdasarkan Jenis Kelamin

\begin{tabular}{|c|c|c|c|}
\hline Kelas & Laki & Perempuan & Jumlah \\
\hline 1 & 47 & 34 & 81 \\
\hline 2 & 37 & 23 & 60 \\
\hline 3 & 20 & 58 & 78 \\
\hline 4 & 52 & 52 & 104 \\
\hline 5 & 52 & 62 & 114 \\
\hline 6 & 66 & 51 & 117 \\
\hline Total & & & 554 \\
\hline
\end{tabular}

b. Jumlah Guru berdasarkan Status, seperti pada Tabel 2.

Tabel 2 Jumlah Guru berdasarkan Status

\begin{tabular}{|l|c|}
\hline Status & Jumlah \\
\hline Guru Tetap Yayasan & 28 \\
\hline Guru Honorer & 7 \\
\hline Total & 35 \\
\hline
\end{tabular}

c. Jumlah Guru berdasarkan Jenjang Pendidikan, seperti pada Tabel 3.

Tabel 3 Jumlah Guru berdasarkan Jenjang Pendidikan

\begin{tabular}{|l|c|}
\hline \multicolumn{1}{|c|}{ Jenjang Pendidikan } & Jumlah \\
\hline S1 atau lebih & 32 \\
\hline Kurang dari S1 & 3 \\
\hline Total & 35 \\
\hline
\end{tabular}

Berdasarkan data di atas dapat dilihat bahwa dengan jumlah murid 582 dan jumlah guru 35, maka dengan asumsi setiap guru mengajar 5 kelas dengan jumlah siswa per kelas 35 orang maka ada 175 siswa yang harus dikelola data nilainya, mulai dari nilai tugas, kuis, Penilaian Tengah Semester maupun Penilaian Akhir Semester dan terakhir adalah nilai rata-rata serta berbagai pengolahan data lainnyauntuk keperluan sekolah.

Pengolahan data untuk keperluan penilaian bukanlah suatu hal yang mudah, apalagi jika data yang dikelola cukup banyak untuk itulah diperlukan kompetensi dalam hal pengolahan data.

\section{Lokasi, Waktu dan lama kegiatan}

Lokasi kegiatan dilakukan di SD Taruna Bakti, J1. LLRE Martadinata No.52, Bandung, Jawa Barat, waktu pelaksanaan adalah pada tanggal 10 September 2019 dari jam 08:00 sampai dengan jam 16:00 WIB.

\section{Pelaksanaan PKM}

Pelaksanaan PKM berupa Pelatihan Microsoft Excel Tingkat Menengah untuk Guru-guru SD Taruna Bakti dilakukan pada tanggal 10 September 2019, jumlah peserta 35 orang. Tim Dosen yang terlibat PKM terdiri dari 3 orang bergantian mengajar pada lab komputer, jika salah satu dosen mengajar 2 orang lagi membantu sebagai asisten. Materi pelatihan yang 
diberikan adalah pengolahan database (mengurutkan data, menampilkan data yang diinginkan), penggunaan rumus-rumus matematika dan logika serta pembuatan grafik yang menunjang proses pengolahan data nilai.

Pelatihan diawali dengan pembukaan dan perkenalan kemudian langsung masuk materi pelatihan. Untuk membuat pelatihan lebih efektif maka file berupa data yang diolah langsung dibagikan kepada para guru peserta pelatihan.

Sesi pertama berisi materi pengolahan data berupa pengurutan data, seperti mengurutkan data berdasarkan nama secara Ascending maupun Descending, mengurutkan nilai berdasarkan nilai tertinggi maupun terendah, menampilkan data yang diperlukan (Filter Data) misalnya menampilkan data siswa dengan nilai yang lebih besar dari 80 dan menampilkan data siswa yang nilainya lebih kecil dari 60. Sesi kedua berisi materi penghitungan nilai rata-rata berupa beberapa rumus matematika seperti Average, SUM, selain itu diajarkan pula bagaimana mengolah data dengan aturan kriteria tertentu misal Nilai Tugas berbobot (40\%), nilai UTS (30\%) dan nilai UAS (30\%). Sesi ketiga berisi materi pembuatan grafik, pada materi ini diajarkan pembuatan grafik dengan beberapa bentuk grafik, seperti grafik berbentuk balok dan pie. Sesi keempat diajarkan rumus logika mulai dari fungsi IF, VLOOKUP, HLOOKUP, LEFT, RIGHT, MID dan beberapa variasi rumus. Isi materi antara lain misalnya menentukan kategori Nilai Rata-rata $>=80$ maka Grade $=$ A, Nilai Rata-rata $>=70$ dan $<80$ maka Grade $=$ B, Nilai Rata-rata $>=60$ dan $<70$ maka Grade $=$ C, Nilai Rata-rata $<60$ maka Grade $=$ D. Sesi kelima sekaligus sesi terakhir adalah evaluasi dan kuesioner. Tim PKM memberikan soal yang harus dikerjakan oleh para peserta pelatihan sebagai bentuk Evaluasi untuk melihat seberapa besar presentase peserta pelatihan menyerap dan mengerti materi pelatihan yang telah diberikan, sedangkan kuesioner diberikan untuk mendapatkan saran dan masukan dari para peserta pelatihan yang akan bermanfaat untuk keperluan pelatihan dimasa yang akan datang.

\section{HASIL DAN PEMBAHASAN}

Hasil dari Pelatihan Microsoft Excel tingkat menengah adalah sebagai berikut:

\section{A. Sesi Pertama}

Sesi Pertama diisi dengan memberikan materi pengolahan data berupa: Pengurutan Data; dan Filter/ Menyaring Data
Sesi Pertama para peserta pelatihan diberikan latihan oleh Tim PKM dengan Kriteria hasil seperti pada Tabel 4

\section{Tabel 4 Hasil Pelatihan Sesi 1}

\begin{tabular}{|c|c|c|c|}
\hline Baik & Cukup & Sedang & Kurang \\
\hline 10 & 20 & 4 & 1 \\
\hline
\end{tabular}

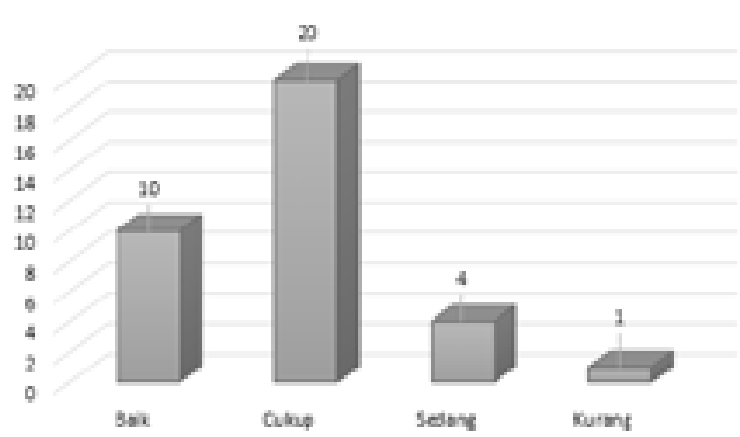

Gambar 1 Hasil Pelatihan Sesi 1

Berdasarkan Tabel 4 dan Gambar 1 di atas maka dapat dilihat bahwa hasil Pelatihan Sesi Pertama dapat dianggap cukup baik karena sebagian besar peserta pelatihan berhasil menguasai materi pelatihan dengan hasil Baik dan Cukup.

\section{B. Sesi Kedua}

Sesi Kedua diisi dengan materi pengolahan data berupa beberapa rumus matematika sebagai berikut: SUM; dan AVERAGE.

Sesi Kedua para peserta pelatihan diberikan latihan oleh Tim PKM dengan Kriteria hasil seperti pada Tabel 5 .

\section{Tabel 5 Hasil Pelatihan Sesi 1}

\begin{tabular}{|c|c|c|c|}
\hline Baik & Cukup & Sedang & Kurang \\
\hline 25 & 10 & 1 & 0 \\
\hline
\end{tabular}

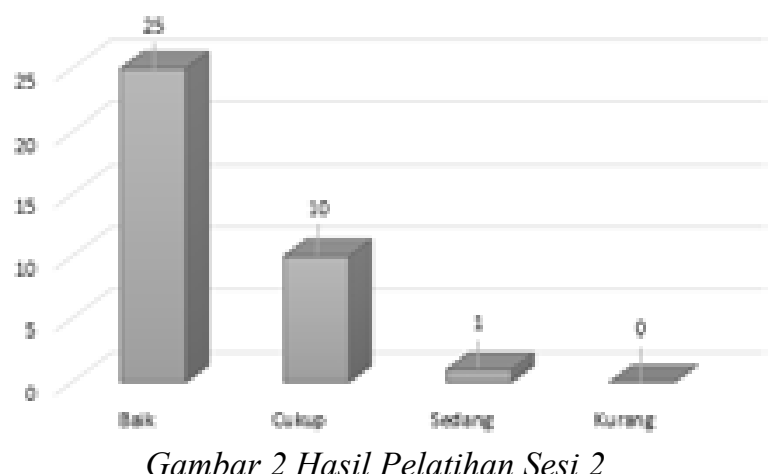

Berdasarkan Tabel 5 dan Gambar 2 di atas maka dapat dilihat bahwa hasil Pelatihan Sesi Kedua dapat dianggap sangat baik karena sebagian besar peserta pelatihan berhasil menguasai materi pelatihan dengan Kategori hasil Baik lebih besar dibandingkan dengan Kategori lainnya. 


\section{Sesi Ketiga}

Sesi Kedua diisi dengan materi pembuatan grafik dengan beberapa bentuk grafik. Beberapa grafik yang dibuat pada pelatihan ini adalah sbb: Grafik berbentuk Balok; dan Grafik berbentuk Pie.

Sesi ketiga para peserta pelatihan diberikan latihan oleh Tim PKM dengan Kriteria Hasil seperti pada Tabel 6.

Tabel 6 Hasil Pelatihan Sesi 3

\begin{tabular}{|c|c|c|c|}
\hline Baik & Cukup & Sedang & Kurang \\
\hline 30 & 4 & 1 & 0 \\
\hline
\end{tabular}

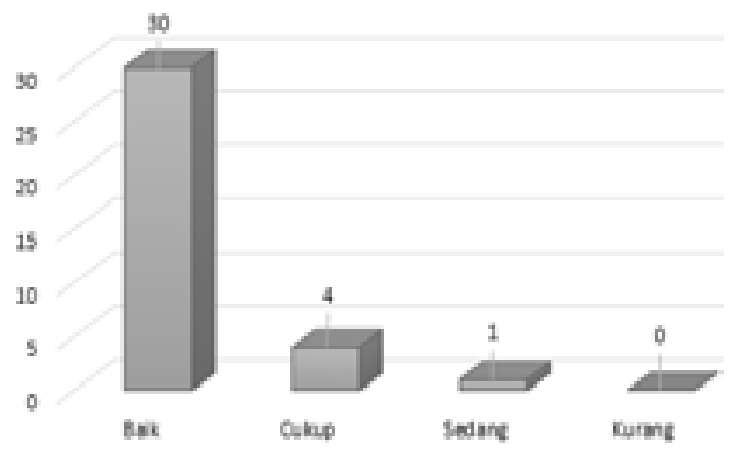

Grafik 3 Hasil Pelatihan Sesi 3

Berdasarkan Tabel 6 dan Gambar 3 di atas maka dapat dilihat bahwa hasil Pelatihan Sesi Ketiga dianggap sangat baik karena sebagian besar peserta pelatihan berhasil menguasai materi pelatihan dengan Kategori hasil Baik lebih besar dibandingkan dengan Kategori lainnya.

\section{Sesi keempat}

Sesi keempat diajarkan rumus logika, seperti fungsi IF, VLOOKUP, HLOOKUP, LEFT, RIGHT, MID dan beberapa variasi rumus. Hasil latihan dari Sesi keempat adalah seperti pada Tabel 7.

Tabel 7 Hasil Pelatihan Sesi 4

\begin{tabular}{|c|c|c|c|}
\hline Baik & Cukup & Sedang & Kurang \\
\hline 10 & 20 & 4 & 1 \\
\hline
\end{tabular}

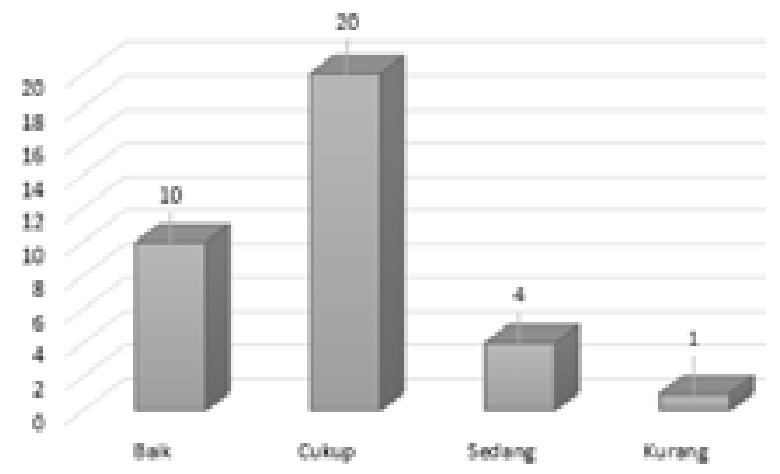

Gambar 4 Hasil Pelatihan Sesi 4

Berdasarkan Tabel 7 dan Gambar 4 di atas maka dapat dilihat bahwa hasil Pelatihan Sesi
Keempat masih dapat dianggap cukup baik karena sebagian besar peserta pelatihan berhasil menguasai materi pelatihan sedangkan yang kurang menguasai pelatihan hanya 1 orang.

\section{E. Sesi kelima}

Sesi kelima sekaligus sesi terakhir adalah evaluasi dan kuesioner. Berdasarkan evaluasi maka dapat disimpulkan bahwa sebagian besar peserta pelatihan telah cukup menguasai materi pelatihan.

Materi pelatihan sesi keempat dianggap materi yang paling sulit diantara materi sesi lainnya, khusus untuk materi tersebut para peserta pelatihan memberikan masukan agar alokasi waktunya ditambah agar mereka dapat lebih menguasai materi tersebut. Namun karena waktu yang terbatas maka masukan tersebut hanya dapat dijadikan catatan oleh TIM PKM sebagai sebuah catatan guna perbaikan materi pelatihan pada PKM yang akan datang.

\section{SIMPULAN}

Berdasarkan pelatihan Microsoft Excel tingkat menengah yang telah diberikan pada PKM ini maka didapat kesimpulan sebagai berikut: Materi Pelatihan telah sesuai dengan kebutuhan para Guru SD Taruna Bakti; Alokasi waktu pelatihan untuk materi pelatihan sesi keempat yaitu Materi tentang fungsi logika berupa rumus-rumus seperti IF, Vlookup dan sebagainya harus lebih lama dibandingkan dengan materi lainnya; dan Modul pelatihan berupa tutorial agar dibuat lebih detail dan jelas agar para guru dapat lebih mudah mempelajarinya.

Hasil akhir dari pelatihan pada PKM ini dapat disimpulkan telah berhasil meningkatkan kompetensi para Guru SD Taruna Bakti dalam hal pengolahan data sehingga mereka siap untuk menerapkan hasil dari pelatihan ini dalam pekerjaan mereka sehari-hari khususnya dalam membuat laporan yang berhubungan dengan pengolahan data nilai.

\section{DAFTAR RUJUKAN}

[1] D. Wahyuni, "Peningkatan Kompetensi Guru Menuju Era Revolusi Industri 4.0”. Kajian Singkat Terhadap Isu Aktual dan Strategis, Pusat Penelitian Badan Keahlian DPR RI, Vol.X, No.24/II/Puslit/Desember/2018

[2] SD Taruna Bakti, 2019 [Online], http://sd.tarunabakti. sch.id/profil-2/ [Accessed:2020]

[3] Data Profile SD Taruna Bakti, 2019 [Online], Available:https://dapo.dikdasmen.kemdikbud. go.id/olah/ 79 B 1832 D 074 C 464 B 0 A 95 , [Accessed:February-2020]. 